\title{
World Review of Nutrition and Dietetics
}

\section{Vol. 83}

Series Editors

Advisory Board
Artemis P. Simopoulos

The Center for Genetics, Nutrition and Health, Washington, D.C., USA

Åke Bruce, Sweden

Ji Di Chen, China

Jean-Claude Dillon, France

J.E. Dutra de Oliveira, Brazil

Claudio Galli, Italy

Ghafoorunissa, India

Demetre Labadarios, South Africa

Eleazar Lara-Pantin, Venezuela

Paul J. Nestel, Australia

Konstantin Pavlou, Greece

A. Rérat, France

V. Rogozkin, Russia

Michihiro Sugano, Japan

Naomi Trostler, Israel

Ricardo Uauy-Dagach, Chile 


\section{The Return of $\omega 3$ Fatty Acids into the Food Supply}

\section{Land-Based Animal Food Products and Their Health Effects}

Volume Editor

A.P. Simopoulos

The Center for Genetics, Nutrition and Health, Washington, D.C.

38 figures and 55 tables, 1998

\footnotetext{
KARER Basel· Freiburg · Paris · London · New York .

New Delhi $\cdot$ Bangkok $\cdot$ Singapore $\cdot$ Tokyo $\cdot$ Sydney
} 


\section{-............................. \\ Artemis P. Simopoulos}

4330 Klingle Street, N.W.

Washington, DC 20016 (USA)

Library of Congress Cataloging-in-Publication Data

International Conference on the Return of $\omega 3$ Fatty Acids into the Food Supply (1997: Bethesda, Md.)

The return of $\omega 3$ fatty acids into the food supply / International Conference on the Return of

$\omega 3$ Fatty Acids into the Food Supply, I. Land-based animal food products, Bethesda, Md.,

Sept. 18-19, 1997; volume editor, A.P. Simopoulos.

(World review of nutrition and dietetics; vol. 83)

Includes bibliographical references and indexes.

Contents: 1. Land-based animal food products and their health effects.

1. Omega-3 fatty acids - Physiological effect - Congresses. 2. Fatty acids in human nutrition -

Congresses. I. Simopoulos, Artemis P., 1933-. II. Title. III. Series.

[DNLM: 1. Fatty Acids, Omega-3 congresses. 2. Dietary Fats, Unsaturated congresses.

3. Food, Fortified congresses. 4. Animal Feed congresses. 5. Animal Nutrition congresses.

QU 90 I611055r 1998]

QP141.A1W59 vol. 83 [QP752.044]

$612.3 \mathrm{~s}-\mathrm{dc} 21\left[613.2^{\prime} 84\right]$

ISBN 3-8055-6694-8 (hardcover: alk.paper)

Bibliographic Indices. This publication is listed in bibliographic services, including Current Contents ${ }^{\circledR}$ and Index Medicus.

Drug Dosage. The authors and the publisher have exerted every effort to ensure that drug selection and dosage set forth in this text are in accord with current recommendations and practice at the time of publication. However, in view of ongoing research, changes in government regulations, and the constant flow of information relating to drug therapy and drug reactions, the reader is urged to check the package insert for each drug for any change in indications and dosage and for added warnings and precautions. This is particularly important when the recommended agent is a new and/or infrequently employed drug.

All rights reserved. No part of this publication may be translated into other languages, reproduced or utilized in any form or by any means electronic or mechanical, including photocopying, recording, microcopying, or by any information storage and retrieval system, without permission in writing from the publisher.

C) Copyright 1998 by S. Karger AG, P.O. Box, CH-4009 Basel (Switzerland)

Printed in Switzerland on acid-free paper by Reinhardt Druck, Basel

ISBN 3-8055-6694-8 


\section{Contents}

\section{Conference Organization}

IX Preface

Part 1: $\omega 3$ Fatty Acids and Health

1 Overview of Evolutionary Aspects of $\omega 3$ Fatty Acids in the Diet Simopoulos, A.P. (Washington, D.C.)

12 Dietary Intake of Long-Chain Polyunsaturated Fatty Acids during the Paleolithic

Eaton, S.B.; Eaton III, S.B. (Atlanta, Ga.); Sinclair, A.J. (Melbourne);

Cordain, L. (Fort Collins, Colo.); Mann, N.J. (Melbourne)

$24 \omega 3$ Fatty Acids and Cardiovascular Disease Leaf, A.; Kang, J.X. (Boston, Mass.)

38 Regulatory Effects of Polyunsaturates on Bone Modeling and Cartilage Function

Watkins, B.A. (West Lafayette, Ind.)

$52 \omega 3$ Fatty Acid Status in Patients with Retinitis pigmentosa Hoffman, D.R.; Birch, D.G. (Dallas, Tex.)

Part 2: $\omega 3$ Fatty Acids in Land-Based Animal Food Products

61 Production of Docosahexaenoic Acid from Microalgae and Its Benefits for Use in Animal Feeds

Barclay, W.; Abril, R.; Abril, P.; Weaver, C.; Ashford, A. (Boulder, Colo.) 
77 Production of Docosahexaenoic Acid-Enriched Poultry Eggs and Meat Using an Algae-Based Feed Ingredient

Abril, R.; Barclay, W. (Boulder, Colo.)

89 Designer Eggs and Their Nutritional and Functional Significance Sim, J.S. (Edmonton)

102 Poultry-Based Alternatives for Enhancing the $\omega 3$ Fatty Acid Content of American Diets

Van Elswyk, M.E.; Hatch, S.D.; Stella, G.G.; Mayo, P.K.;

Kubena, K.S. (College Station, Tex.)

116 Single Cell Oil Sources of Docosahexaenoic Acid: Clinical Studies Kyle, D.J.; Arterburn, L.M. (Columbia, Md.)

132 w3 Enriched Pork Howe, P.R.C. (Wollongong)

144 Enrichment of Beef with $\omega 3$ Fatty Acids Mandell, I.B.; Buchanan-Smith, J.G.; Holub, B.J. (Guelph)

160 Docosahexaenoic Acid-Enriched Milk Wright, T.; McBride, B.; Holub, B. (Guelph)

$166 \omega 3$ Products: From Research to Retail Born, F. (Abbotsford)

Part 3: Companion Animal Nutrition

176 Utilization of $\omega 3$ Fatty Acids in Companion Animal Nutrition Hayek, M.G.; Reinhart, G.A. (Lewisburg, Ohio)

186 Metabolism of $\alpha$-Linolenic Acid from Flaxseed in Dogs Bibus, D.; Stitt, P.A. (Manitowoc, Wisc.)

Part 4: Scientific and Policy Aspects

199 Global Food Fortification Perspectives of Long Chain $\omega 3$ Fatty Acids Newton, I.S. (Parsippany, N.J.)

210 Regulatory Aspects of $\omega 3$ Fatty Acid Labelling in Canada Holub, B.J. (Guelph)

$215 \omega 3$ Fatty Acids - An Australian Perspective Howe, P.R.C. (Wollongong)

219 Redefining Dietary Reference Values and Food Safety Simopoulos, A.S. (Washington, D.C.)

Poster Abstracts

223 Utilization of $\omega 3$ Fatty Acids in Ruminants Ashes, J.R.; Gulati, S.K.; Scott, T.W. (Sydney) 
224 Use of Marine Resources to Enrich the Most Consumed Animal Origin Products in Mexico with $\omega 3$ Fatty Acids

Carrillo, S.; Carranco, M.E.; Arellano, L.; Ramos, F.; Cortez, A.; de la Pena, M.; Perez-Gil, F. (Mexico)

225 The Fatty Acid Composition of Muscle, Brain, Marrow and Adipose Tissue in Elk: Evolutionary Implications for Human Dietary Lipid Requirements

Cordain, L.; Martin, C.; Florant, G. (Fort Collins, Color.);

Watkins, B.A. (West Lafayette, Ind.)

226 Fish Consumption May Predict a Lower Prevalence of Major Depression: A Cross-National Analysis Hibbeln, J.R.; Salem, N. Jr. (Rockville, Md.)

227 Fish Oils as Potential Immune-Enhancers in Clinical Enteral Nutritional Support: A Survey of Professional Users

Katz, R. (Bethesda, Md./Baltimore, Md.)

228 Present Estimates of $\omega 3$ Fatty Acid Intake in the US Kris-Etherton, P.M.; Taylor, D.S.; Yu, S.; Moriarty, K.; Fishell, V.; Morgan, R.; Zhao, G. (University Park, Pa.); Heimbach, J.T.; Etherton, T.D. (Arlington, Va.)

229 Incorporation of $\omega 3$ Fatty Acid-Enriched Eggs in Low Fat Diets of Hypercholesterolemic Humans

Lewis, N.M.; Schalch, K.; Scheideler, S.E. (Lincoln, Nebr.)

230 Marine Crustacea Red Crab (Pleuroncodes planipes) as a Potential Source of $\omega 3$ Fatty Acids

Castro-Gonzalez, M.I.; Perez-Gil, R.F.; Silencio, B.J.L.; Montano, B.S.;

Aurioles-Gamboa, D. (Mexico)

230 Factors Affecting $\omega 3$ Fatty Acid Deposition from Dietary Flaxseed and Elongation of C18:3 to C22:6 in the Egg

Scheideler, S.E.; Froning, G.W.; Jaroni, D. (Lincoln, Nebr.)

231 Distribution of $\omega 3$ Fatty Acid Levels and Prevalence of Low Levels of w3 Fatty Acids in Subjects Participating in the Framingham Offspring Heart Study Cycle 4

Siguel, E.; MacKenzie, A. (Brookline, Mass.)

233 o3 Fatty Acids in Meat Raise Plasma Levels of Eicosapentaenoic and Docosapentaenoic Acids

Sinclair, A.J.; Mann, N.J. (Melbourne)

234 Effect of Feeding Flaxseed to Laying Hens on the Hen Performance and Fatty Acid Composition of Yolk Eggs

Yannakopoulos, A.L.; Tserveni-Gousi, A.S.; Yannakakis, E. (Thessaloniki)

235 Author Index

236 Subject Index 


\title{
Conference Organization \\ Organized by The Center for Genetics, Nutrition and Health
}

\author{
Conference Cochairs
}

Artemis P. Simopoulos, MD (USA)

Bruce Holub, PhD (Canada)

Norman Salem, Jr., PhD (USA)

Organizing Committee

Artemis P. Simopoulos, MD (USA), Chairman

William R. Barclay, PhD (USA)

Mary E. Van Elswyk, RD, PhD (USA)

Bruce Holub, PhD (Canada)

Peter Howe, $\mathrm{PhD}$ (Australia)

Uri Sadot, $\mathrm{PhD}$ (Israel)

Norman Salem, Jr., PhD (USA)

Jeong S. Sim, PhD (Canada)

\section{Cosponsors}

The Center for Genetics, Nutrition and Health

National Institute on Alcohol Abuse and Alcoholism - NIH

National Institute of Child Health and Human Development - NIH

Designer Egg Producers' Association International

ENRECO, Inc. (Essential Nutrient Research Co.)

F. Hoffmann-La Roche AG

Flax Council of Canada

Martek Biosciences Corp.

OmegaTech, Inc.

Pilgrim's Pride - EggsPlus

Roche Vitamins Inc.

The Iams Co.

The NutraSweet Kelco Co. 


\section{............................. \\ Preface}

Studies on the evolutionary aspects of diet suggest that major changes have taken place in our food supply since the agricultural revolution 10,000 years ago. The change in animal feeds that came along with the domestication of animals changed the composition of meats, particularly the content of essential fatty acids ( $\omega 6$ and $\omega 3$ fatty acids). The meat of animals in the wild has less total fat, less saturated fat and more polyunsaturated fat with a ratio of $\omega 6$ to $\omega 3$ fatty acids of less than $2 / 1$. The change became even greater with the advent of modern agricultural practices and agribusiness. Using grains to feed cattle instead of grazing and eating grass has led to increases in the $\omega 6$ fatty acids and decreases in the $\omega 3$ fatty acid content of meat. Similar changes have occurred in the composition of eggs, poultry, and in fish from aquaculture. Because wild plants have a ratio of linoleic acid to $\alpha$-linolenic acid of less than 1 , the overall ratio of $\omega 6$ to $\omega 3$ was less than $2 / 1$ prior to the agricultural revolution.

These changes have been widely reported in the scientific literature. Industry has recognized the need to alter animal feeds in order to reverse this change. Today one can find products consistent with the evolutionary aspects of diet in the American market, such as $\omega 3$-enriched eggs with the $\omega 6 / \omega 3$ ratio closer to eggs under completely natural conditions. The $\omega 3$ enrichment was accomplished by adding to chicken feed $\omega 3$ fatty acids in the form of fish meal, or flaxseed or docosahexaenoic acid (DHA) produced from algae. This change is not limited to the US market. $\omega 3$-enriched eggs can be found in various parts of the world, in Canada, Brazil, Australia, Israel, Greece, Germany, and other European countries.

As a result of the above developments, and the recognition of the important role of $\omega 3$ fatty acids in growth and development and in health and disease, it was thought timely to hold the 1st International Conference on the Return of $\omega 3$ Fatty Acids into the Food Supply: I. Land-Based Animal Food 
Products and Their Health Effects, at the Natcher Conference Center, National Institutes of Health in Bethesda, Md., Sept 18-19, 1997.

The conference, organized by the Center for Genetics, Nutrition and Health, was sponsored by the Center for Genetics, Nutrition and Health, the National Institute on Alcohol Abuse and Alcoholism-NIH, the National Institute on Child Health and Human Development-NIH, Designer Egg Producers' Association International, ENRECO, Inc. (Essential Nutrient Research Company), F. Hoffmann-La Roche AG, Flax Council of Canada, Martek Biosciences Corporation, OmegaTech, Inc., Pilgrim's Pride - Eggs Plus, Roche Vitamins Inc., the Iams Company, and the NutraSweet Kelco Company.

The conference, limited to 100 persons, was attended by scientists from Argentina, Australia, Belgium, Canada, France, Greece, Israel, Mexico and the US.

The first session was on the relationship of $\omega 3$ fatty acids in health and selected disease states. It began with presentations on the evolutionary aspects of diet with emphasis on the $\omega 3$ fatty acids. Dr. Simopoulos gave an overview of the evolutionary aspects of diet and pointed out that the $\omega 3$ fatty acids are found in every meal of the traditional Greek diet, as it was during the Paleolithic period when our genetic profile was established, which may account for the lowest rates of cardiovascular disease and cancer in the Greek population as noted in the Seven Countries Study. Dr. Eaton reviewed the evidence and the need to take into consideration the findings of the Paleolithic diet in the development of dietary recommendations. Dr. Leaf presented a thorough review of the role of $\omega 3$ fatty acids in cardiovascular disease, and Dr. Bruce Watkins presented rather provocative but persuasive data on the effects of polyunsaturated fatty acids on bone modeling and cartilage function. His work has important implications in the prevention of osteoporosis since $\omega 6$ fatty acids increase the production of prostaglandin $\mathrm{E}_{2}$ which in turn increases osteoclastic activity. A number of diseases are due to inborn errors of essential fatty acid metabolism. Retinitis pigmentosa is such a genetic disorder. Dr. Hoffman reviewed the data and described the ongoing intervention trials with DHA.

The second session consisted of presentations on the development of $\omega 3-$ enriched products and the sources of $\omega 3$ fatty acids for animal feeds. Dr. Barclay discussed the production of DHA from microalgae and pointed out its beneficial use in animal feeds. He was followed by Dr. Abril who described the production of DHA-enriched poultry eggs and meat using the algae-based feed ingredient. Dr. Sim reviewed his studies in which poultry products are enriched in $\omega 3$ fatty acids by using flaxseed. Dr. Sim gave an extensive presentation of his clinical studies with $\omega 3$-enriched eggs and their beneficial effects 
in human subjects. This theme was continued by Dr. Van Elswyk who spoke on poultry-based alternatives for enhancing the $\omega 3$ fatty acid content of American diets. Dr. Kyle reviewed his experience with the production of DHA from single cell oil sources of DHA and the clinical studies with DHA-enriched infant formula.

Dr. Howe reviewed his data on $\omega 3$-enriched pork and emphasized the need to balance $\omega 3$ enrichment without adversely affecting the taste of pork. He presented data indicating that feeds containing 13 fatty acids can be withdrawn 4 weeks prior to slaughter without compromising the $\omega 3$ enrichment, yet preventing alterations in the taste of pork or its physical characteristics.

Dr. Mandel discussed the studies leading to the enrichment of beef with $\omega 3$ fatty acids, and Dr. Holub spoke on the natural enrichment of cow's milk with DHA. This session ended with a presentation by Mr. Born, who discussed the issues involved in $\omega 3$-enriched products as they move from research to retail.

$\omega 3$ fatty acid-enriched products are not limited to human consumption. Therefore, two papers discussed the status of $\omega 3$-enriched products in companion animal nutrition. Dr. Hayek presented studies with $\omega 3$-enriched products showing improvement in various disease states, and Mr. Stitt presented data on the rapid absorption and elongation of $\alpha$-linolenic acid in dogs.

The fourth session was on the Scientific and Policy Aspects. Mr. Newton gave an overview on the status of Global Food Fortification Perspectives of Long Chain $\omega 3$ Fatty Acids. Dr. Holub discussed the $\omega 3$ fatty acid status in Canada. Canada has specific recommendations for $\omega 3$ fatty acids. Dr. Howe discussed the situation in Australia and Dr. Lee discussed the situation in the US. The US does not have dietary recommendations for $\omega 3$ fatty acids and the nutrition label does not separately list the $\omega 6$ and $\omega 3$ polyunsaturated fatty acids.

There was an extensive discussion on these issues. Particularly the need to include $\omega 3$ fatty acids in infant formula.

Dr. Simopoulos addressed two issues: (1) dietary recommendations and genetic variation, and (2) the need to redefine food safety to include food composition. Dr. Simopoulos spoke on the need to redefine the dietary reference values by taking into consideration not only the evolutionary aspects of diet, but also genetic variation. She used as an example the folate data. The dietary reference values for folate, as for other nutrients, are targeted to the general and supposedly normal population, and do not take into consideration consumers with special needs, such as those with genetic abnormalities or diseases. In the case of folate, $5-15 \%$ of the general population are homozygous for a thermolabile variant of 5,10-methylenetetrahydrofolate reductase 
(C677T) which causes mild hyperhomocysteinemia and is positively associated with the development of vascular disease and the risk of neural tube defects. Individuals with C677T have lower red cell folate concentrations and the current reference daily intake is not adequate since they have increased needs. It is possible that other genetic variants interact with particular nutrients, which casts doubt on the validity of assuming 'normality' for nutrient requirements in any population.

There is a need to redefine food safety. Food safety should not be limited to avoiding contamination with bacteria, viruses, protozoa, and toxins. Food safety must take into consideration changes in food composition. This principle is even more important when we have a food supply, such as the current Western diet, that has an imbalance in the $\omega 6$ and $\omega 3$ essential fatty acids and is high in trans fatty acids, increasing the risk for chronic diseases. Furthermore, when new nutrients are introduced into the food supply whose structure has been altered, i.e. trans fatty acids, or the ratio of esential nutrients has changed as is currently the case with the $\omega 6$ and $\omega 3$ fatty acid imbalance, the shortand long-term effects and safety need to be establushed.

The adverse effects of trans fatty acids on lipid metabolism and the lack of $\omega 3$ fatty acids in infant formulas highlight the importance of taking into consideration nutritional effects on both growth and neurological development and on chronic disease processes when designing new food products. Just as we are required to develop Environmental Impact Statements whenever environmental changes are contemplated, we should be required to develop Nutritional Impact Statements for novel foods relative to their safety in growth and development and in health and disease, particularly chronic diseases.

This conference was the first to bring together scientists from academia, government and industry to discuss the return of $\omega 3$ fatty acids into the food supply. The published proceedings cannot capture the thoughtful discussions and the excitement of active participation that took place within the scientific sessions and during the social events, but the interested reader will find the papers stimulating, groundbreaking, and useful.

These proceedings should be of interest to physicians, veterinarians, nutritionists, dieticians, food technologists, agriculturalists, food policy-makers, consumer advocates, lawyers and entrepreneurs.

Artemis P. Simopoulos 